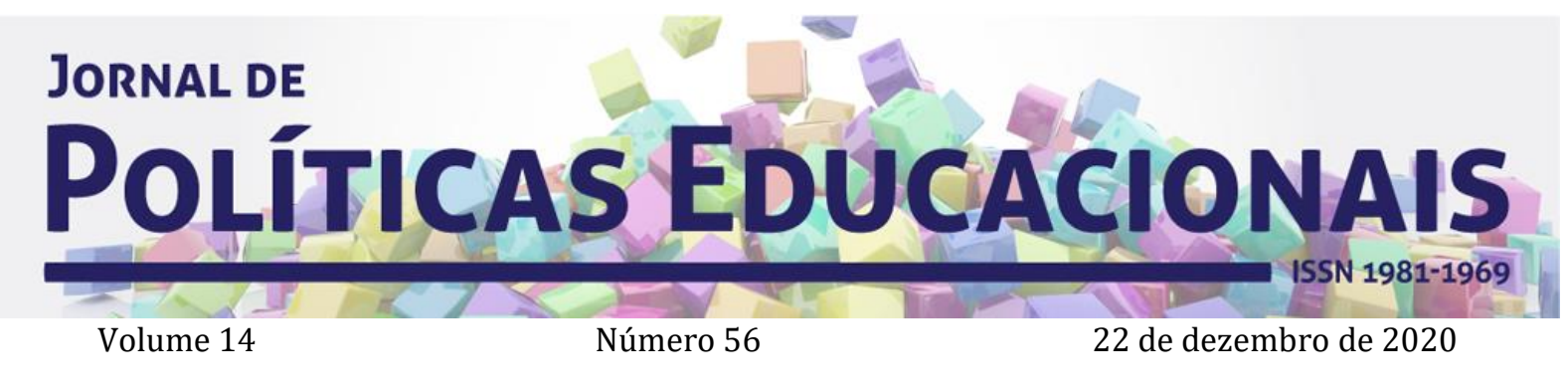

\title{
Da Burocracia à Profissão: Reconstruindo o Setor Educacional para o Século 21
}

\section{From Bureaucracy to Profession:Remaking the Educational Sector for the Twenty-First Century}

\section{De la burocracia a la profesión: Rehaciendo el sector educativo para el siglo XXI}

Citação: MEHTA, J. Da burocracia à profissão: Reconstruindo o Setor Educacional para o Século 21. Jornal de Políticas Educacionais. V. 14, n. 01. Dezembro de 2020.

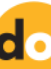

http://10.5380/jpe.v14i0.78849

\begin{abstract}
Resumo
0 artigo examina os desafios enfrentados pela escola americana e as razões para o fracasso persistente das reformas escolares para alcançar resultados educacionais bem-sucedidos em larga escala. Com base em pesquisa de uma variedade de campos e disciplinas, mostra uma perspectiva "setorial" sobre a reforma educacional, explorando como essa mudança de pensamento poderia ajudar os diferentes atores interessados na educação a produzir práticas de qualidade em todo o país.

Palavras-chave: políticas educacionais, reformas educacionais, profissionalização.
\end{abstract}

\begin{abstract}
The article examines the challenges faced by American schooling and the reasons for persistent failure of American school reforms to achieve successful educational outcomes at scale. Building on research from a variety of fields and disciplines, shows a "sectoral" perspective on education reform, exploring how this shift in thinking could help education stakeholders produce quality practice across the nation.
\end{abstract}

Keywords: education policies, education reforms, professionalization.

\section{Resumen}

El artículo examina los desafíos que enfrenta la educación estadounidense y las razones del fracaso persistente

\footnotetext{
1 Ph.D., Harvard University, (2006). Harvard Graduate School of Education. Cambridge, MA. Estados Unidos da América. Orcid: https://orcid.org/0000-0002-3663-3948 E-mail: jal_mehta@gse.harvard.edu
} 
de las reformas escolares estadounidenses para lograr resultados educativos exitosos a escala. Sobre la base de la investigación de una variedad de campos y disciplinas, muestra una perspectiva "sectorial" sobre la reforma educativa, explorando cómo este cambio de pensamiento podría ayudar a los interesados en la educación a producir prácticas de calidad en todo el país.

Palabras clave: políticas educativas, reformas educativas, profesionalización.

\section{Introdução ${ }^{2}$}

Alcançar altos resultados educacionais em grande escala é sem dúvida o maior desafio para o ensino americano. Neste ensaio sugiro que estamos fazendo a pergunta errada. Quando as reformas não se desenvolvem tanto ou tão rápido quanto esperamos, perguntamos: "0 que há de errado com a reforma?" quando, em vez disso, deveríamos perguntar: "O que há de errado com o setor?" A raiz do problema é que o setor educacional como um todo é organizado em torno de um sistema central que funciona mais como uma burocracia do que como uma profissão; estamos tentando resolver um problema que requer habilidade e experiência profissional usando alavancas burocráticas de requisitos e regulamentos. Muitos dos problemas específicos que vemos hoje - grande variabilidade nos níveis de habilidade de professores nas diferentes salas de aula, falha em disseminar boas práticas entre as escalas locais do sistema, a ausência de uma "infraestrutura educacional" para apoiar a prática, falha em capitalizar o conhecimento e a habilidade dos bons professores e as relações desconfiadas e improdutivas entre os formuladores de políticas e os profissionais - são subprodutos da forma em que o setor educacional foi moldado. Particularmente à medida que as demandas de escolaridade aumentam, esperase que todos os alunos sejam capazes de pensar criticamente para participar da vida moderna, precisamos transformar o sistema de uma burocracia da Era Progressiva em uma profissão do século XXI.

Nas páginas que se seguem, examino as raízes da organização do setor educacional americano contemporâneo: como sua forma inicial afetou seu desenvolvimento, as implicações dessa forma para nossas dificuldades atuais em alcançar práticas bemsucedidas em escala e as maneiras pelas quais um um setor educacional reconcebido estaria mais bem equipado para ajudar todos os alunos a aprender. Este argumento baseia-se e integra pesquisas de diversas arenas - trabalho sobre os requisitos técnicos do ensino, a sociologia das profissões, o desenvolvimento histórico da escolaridade nos

\footnotetext{
2 Artigo originalmente publicado em: Harvard Educational Review Vol. 83 No. 3 Fall 2013. Tradução: Andréa Barbosa Gouveia (NUPE/PPGE/UFPR)
} 
Estados Unidos e pesquisas comparativas sobre líderes educacionais internacionais - para avançar em uma perspectiva setorial sobre o porquê temos lutado para alcançar o sucesso generalizado na educação americana e como um setor educacional refeito poderia resolver melhor nossos problemas no futuro.

\section{Mudando a lente: do foco em programas para reinventar o setor educacional.}

Existem duas perspectivas principais que são frequentemente empregadas na discussão da melhoria educacional em escala. A primeira é tomar-se o programa ou política como unidade de análise. Desse ponto de vista, a questão inicial é se a política está alcançando o impacto pretendido sobre os resultados. Um programa ou política que demonstra sucesso em um determinado contexto é então escolhido para ser replicado em outros contextos. A lógica é atraente porque permite a experimentação antes da implementação em uma escala mais ampla e se baseia na lógica da ciência e nas ferramentas de avaliação rigorosa. A abordagem também é fundamentalmente consistente com imperativos democráticos, já que sustenta-se em legisladores eleitos fazendo leis e servidores públicos não eleitos (neste caso, professores) que os implementam.

Apesar das virtudes, o problema com essa lógica é que ela não funciona bem, pelo menos se o objetivo for uma melhoria real em escala. 0 padrão típico é o seguinte. Alguns conjuntos de atributos são mostrados para produzir um resultado em um local usado como piloto, em pequena escala. Os legisladores ficam entusiasmados com a ideia e procuram traduzir o que aconteceu no local inicial em um programa ou política que visa atingir o que o piloto fez. Mas quando a iniciativa é implementada em uma escala mais ampla, os atores em outros locais não têm o mesmo nível de experiência e investimento na ideia como os atores envolvidos no piloto (SCHNEIDER \& McDONALD,2007). Partes importantes de conhecimento prático detalhado (métis) que fizeram a ideia inicial funcionar não são capturadas pelas diretrizes relativamente amplas do programa. As diferenças de contexto fazem com que o que funcionou no local A não funcione tão bem no local B. As avaliações concluem que o efeito final do programa como um todo é muito pequeno ou nulo (ROSSI, 1987), ainda que alguns locais possam ter tido resultados positivos significativos. Esses locais de sucesso tendem a ser aqueles com lideranças fortes e maior adesão e fidelidade ao design original ou, que descobriram maneiras de 
adaptá-lo a seus contextos específicos. 0 sucesso desses poucos se torna a base para a próxima iniciativa, com um esforço para isolar "o que funcionou" nesses locais e torná-lo a base para a próxima rodada de políticas, começando o ciclo novamente. Charles Payne (2008) chama isso de padrão "muita reforma para pouca mudança" nos esforços de melhoria escolar.

A segunda perspectiva de melhoria em escala incorpora uma lógica mais ascendente, focando menos na política e mais na reprodução das condições organizacionais. A ideia, novamente, é identificar o que funciona em um local e, em seguida, fazer com que a organização-mãe - como uma organização de gerenciamento regulamentar - copie lenta e cuidadosamente esses elementos em locais adicionais. $\mathrm{Na}$ melhor das hipóteses, uma atenção muito específica é dada ao conhecimento prático detalhado necessário para fazer a iniciativa funcionar, e esse conhecimento é transferido de um local para outro (PEAURACH, 2011).

Os pontos fortes e fracos dessa abordagem são a imagem invertida da anterior. A principal vantagem é que, com um ritmo mais lento, mais atenção aos detalhes, processos mais escalonados de transferência de conhecimento e, potencialmente, a capacidade de escolher locais com circunstâncias mais favoráveis, essas redes podem, no seu melhor, fornecer resultados significativamente maiores em avaliações convencionais do que a abordagem programática. Mesmo deixando de lado as críticas pedagógicas, como aquelas dirigidas à em escolas "sem pretextos" (GOODMAN, 2013), existem pontos fracos dessa abordagem considerando seus próprios termos. Uma é que para ser bem-sucedido, você precisa fazer muitas coisas diferentes exatamente da maneira certa - e, portanto, o ritmo é, necessariamente, extremamente lento. Por exemplo, em quase vinte anos de existência, as principais redes charter ainda têm apenas cerca de cem escolas - em uma nação com cem mil escolas (TOCH, 2009). Outra limitação é que, até o momento, muito do que faz essas empresas funcionarem é a seleção de jovens dispostos a trabalhar longas horas, novamente dificultando a concepção como essa abordagem pode ter sucesso em escala real. No geral, nem de cima para baixo, nem abordagens de baixo para cima têm sido capazes de produzir bons resultados em toda a nação.

Eu argumento aqui que essas não são as únicas duas opções. Seria melhor ter uma visão mais ampla e ver o problema de uma perspectiva setorial, em vez de uma perspectiva de replicação programática ou organizacional. Do ponto de vista setorial, a chave para a melhoria não são as iniciativas individuais, mas sim as características que 
organizam o trabalho do setor como um todo. Essas características incluem: (1) quem é atraído para trabalhar no setor, como são selecionados e como são treinados; (2) se há uma base de conhecimento acumulada que orienta o trabalho; (3) se existem processos em vigor para garantir que o conhecimento seja usado de forma consistente no local de entrega; e (4) se as etapas acima mencionadas estão alinhadas em torno de um sistema abrangente de responsabilidade.

Todos os campos precisam de uma maneira de realizar essas quatro funções, mas diferentes ocupações variam muito em quão bem-sucedidos são em cada uma e onde escolhem colocar sua ênfase. Vendo a medicina americana como um setor, por exemplo, vemos que há um alto grau de seletividade em quem entra no campo, treinamento extensivo fundamentado em uma base de conhecimento robusta e altamente desenvolvida e processos organizacionais, como rotinas hospitalares que garantem que este conhecimento é utilizado na prática cotidiana, mas existem mecanismos relativamente fracos de análise de resultados finais (ou seja, não há um programa como "Nenhum paciente deixado para trás").

Por outro lado, na educação americana, embora esteja-se excessivamente focado na responsabilidade pelos resultados, não construímos o capital humano, o conhecimento ou os processos organizacionais necessários para atingir esses objetivos. Embora medicina e educação não sejam análogos exatos - entre outras diferenças, a medicina é um campo mais científico e em que os fins são menos contestados - a comparação é útil porque destaca as maneiras pelas quais a educação é comparativamente muito menos robusta no desenvolvimento dos processos necessários para produzir trabalho qualificado de forma consistente.

De uma perspectiva setorial, a educação americana é organizada ao contrário em uma comparação com a medicina e com sistemas educacionais de alto desempenho ao redor do mundo. Por organizado ao contrário, quero dizer que buscamos realizar no final - responsabilizando os professores - o que não fizemos no início do processo - construir um sistema que pode ser razoavelmente esperado para criar bons resultados de forma consistente. No sistema educacional americano, não recrutamos professores do nível superior de desempenho acadêmico; nós provemos os professores com treinamento limitado, eles estão equipados com pouco conhecimento utilizável e os enviamos para trabalhar em escolas que, pelos padrões internacionais, têm níveis elevados de pobreza infantil e fracos apoios em termos de proteção social. 
Esses fatores contribuem para uma grande variação nos resultados dos alunos, de professor para professor e de escola para escola, com resultados particularmente desanimadores em escolas que atendem a grandes proporções de alunos em situação de pobreza elevada. Por sua vez, os formuladores de políticas olham para essas escolas com problemas e procuram intervir, responsabilizando mais diretamente escolas e professores pelos resultados. Isso cria um clima de desconfiança entre os gestores de políticas e os profissionais, por um lado tem-se formuladores de políticas que procuram monitorar e dirigir profissionais que eles julgam que estão falhando em fornecer aos alunos uma educação decente e, de outro lado, profissionais que se ressentem dos formuladores de políticas pelo que consideram uma culpa mal colocada e demandas mal informadas. Esta é a espiral descendente do sistema educacional americano que está na moda hoje: subprofissionalização e fraco desempenho, levam a uma maior regulamentação, responsabilidade externa e desconfiança, o que por sua vez torna a profissão menos atraente para pessoas talentosas, começando assim a espiral novamente.

O que o setor de educação americano precisa é o oposto - uma espiral ascendente, que é o que caracteriza várias nações com forte desempenho em comparações educacionais internacionais. 0 padrão nessas nações é recrutar professores do terço superior dos graduados universitários, prepará-los extensivamente e fornecer apoio no contexto de Estado de Bem-Estar para estudantes em situação de pobreza elevada (BARBER \& MOURSHED, 2007; OECD, 2010). A dinâmica desses sistemas é muito diferente do que vemos nos Estados Unidos: professores talentosos e preparados, combinados com alunos motivados e bem apoiados, produzem bons resultados no nível da escola, o que leva atores externos, incluindo formuladores de políticas, a ver as escolas mais como parceiras na melhoria e menos como entidades com falhas que precisam ser monitoradas e controladas. Essas dinâmicas produzem um maior nível de profissionalização e responsabilidade interna, o que cria confiança e diminui a regulamentação de cima para baixo, uma mudança que torna o campo da educação mais atraente para candidatos academicamente fortes, dando continuidade ao ciclo positivo (MEHTA, 2013).

Oferecendo uma abordagem mais promissora para as questões de escala, a perspectiva setorial também traz à tona uma série de aspectos do contexto que são amplamente invisíveis da perspectiva programática mais tradicional. Enquanto a visão programática considera a estrutura atual do sistema - estados supervisionando distritos, 
distritos supervisionando escolas, escolas supervisionando professores - a perspectiva setorial imagina que existem diferentes maneiras pelas quais os profissionais e o Estado podem interagir, especialmente se esses profissionais fossem mais organizados como membros de uma profissão de pleno direito. Além disso, enquanto a visão programática chama a atenção para os atores que têm autoridade educacional formal (estados, distritos, diretores e professores), a visão setorial nos pede para olhar mais amplamente para a ampla gama de atores que atualmente fazem, ou poderiam potencialmente influenciar a educação, incluindo, por exemplo, instituições de preparação de professores, sindicatos de professores, pesquisadores, a comunidade filantrópica e o grande setor comercial que fornece muitos dos currículos, avaliação e desenvolvimento profissional da educação americana. $\mathrm{Na}$ perspectiva setorial, as questões centrais incidem sobre o nível de qualidade apresentado por cada um desses atores e em que medida eles, de modo geral, estão alinhados a serviço dos objetivos educacionais.

Finalmente, a perspectiva programática silencia amplamente sobre questões de política, história e poder. Seu pressuposto é que embora a política desempenhe um papel quando a iniciativa é escolhida, o estágio seguinte seria idealmente um processo apolítico de implementação. Em contraste, a perspectiva setorial enfatiza como os diferentes atores do campo se desenvolveram, por que fazem o que fazem e como interagem uns com os outros em um ambiente político complexo e contestado. A perspectiva setorial, então, é que uma melhoria significativa em grande escala exigirá o envolvimento desses vários atores (ou a criação de novos atores) para trabalharem juntos de maneiras alinhadas que sejam consistentes com seus interesses organizacionais e que também promovam o setor como um todo.

\section{A forma do sistema escolar: burocracia versus profissão}

O setor educacional contemporâneo está alicerçado em profundas raízes históricas. Embora uma descrição completa desses antecedentes esteja além do escopo deste artigo, um breve esboço do contexto histórico pode ajudar a iluminar a natureza dos desafios que enfrentamos hoje.

Particularmente importante para essa história é a distinção entre os modos burocráticos e profissionais de organização do trabalho. Em termos de um tipo ideal, uma burocracia é organizada em torno de uma lógica de controle gerencial, com o poder amplamente concentrado no topo e os trabalhadores vistos como amplamente 
intercambiáveis na base. Em tal sistema, a padronização é assegurada pela criação de regras e procedimentos elaborados que cobrem a gama de circunstâncias que os atores do sistema provavelmente enfrentarão. Esse sistema é apropriado para o trabalho de rotina, como em uma fábrica, em que os processos podem ser razoavelmente bem especificados e as ações claramente prescritas. Em contraste, um modelo profissional é mais apropriado para o trabalho não rotineiro que requer altos níveis de habilidade e especialização (ROWAN 1990). O ensino exige que os professores tenham um conhecimento profundo de suas matérias e de como os alunos as entendem, bem como uma capacidade de tomada de decisão interativa em tempo real em situações imprevisíveis. Na verdade, Philip Jackson (1968) estimou que os professores tomam milhares de microdecisões no decorrer de um determinado dia. Por essas razões, o ensino é mais apropriadamente pensado como um trabalho profissional, caracterizado por níveis profundos de conhecimento e expertise, padrões compartilhados profissionalmente de prática apropriada e o uso de julgamento e discricionariedade na aplicação desse conhecimento comum a situações particulares.

A Tabela 1 ilustra as diferenças entre os dois modos de organização social. Embora muitos estudiosos tenham investigado essas diferenças (PERROW, 1967; ROWAN, 1990), a linguagem e a organização dessa tabela baseiam-se principalmente em Mintzberg (1993). As diferenças nos requisitos técnicos do trabalho, qualificados ou rotineiros, por sua vez, estão ligadas às diferenças na forma como o trabalho é organizado. Em particular, o mecanismo que garante a consistência dos resultados varia: em um trabalho burocrático segue-se processos de rotina (por exemplo, nas linhas de montagem), enquanto em um trabalho profissional está construído sobre o conhecimento de como o trabalho deve ser feito, com pessoas formadas nesse conhecimento, licencia-se apenas aqueles que dominam esse conhecimento e, em seguida, cria-se normas e padrões contínuos que orientam o trabalho na prática. A academia, por exemplo, usa o $\mathrm{PhD}$ para certificar que os novos participantes atenderam às expectativas iniciais de um determinado campo e, em seguida, a revisão por pares para garantir que o trabalho em andamento seja consistente com as normas desse campo. Essas diferenças na natureza do trabalho e em sua organização estão ligadas a diferenças de poder político. Em empresas burocraticamente organizadas, o poder é amplamente concentrado naqueles que exercem supervisão gerencial; mas nas profissões, o profissional assume um poder significativo com base em sua experiência, o que então o habilita a se defender perante o estado. 
Para complicar ainda mais as coisas, o ensino americano se enquadra em um tipo particular de burocracia. Não é realmente um modelo de estilo de fábrica em que cada movimento do professor é rigidamente prescrito por entidades externas, embora tenha havido períodos em que os legisladores tentaram elaborar currículos e transformar o ensino em trabalho de linha de montagem, incluindo a maneira como alguns distritos e escolas implementaram No Child Left Behind (AU, 2011). O padrão histórico mais geral no ensino americano, entretanto, tem sido uma burocracia fracamente acoplada que é hierárquica em sua distribuição de autoridade, mas bastante fraca em sua especificação dos procedimentos reais que governam a prática (WEICK, 1976).

Funcionários distritais e, mais tarde, estaduais e federais prescrevem o que deve ser ensinado, em que ritmo e com quais consequências, mas a partir destas os professores têm considerável liberdade para decidir como atingir esses fins. Neste arranjo, a criação de um núcleo técnico comum que possa produzir de forma confiável tais resultados não é realmente responsabilidade de ninguém. Ironicamente, esse arranjo é então celebrado como "apertado nas pontas" e "solto nos meios" (NATIONAL GOVERNORS ASSOCIATION, 1986; OSBORNE \& GABLER, 1992), como se desse a todos um papel apropriado no sistema, quando na verdade o que frequentemente significa, é que na prática, o poder superior está pedindo ao poder inferior para fazer algo que nenhum dos dois sabe realmente fazer.

Quadro 1 - Modos de organização burocráticos e profissionais

\begin{tabular}{|l|l|l|}
\hline Dimensão & Modelo burocrático & Modelo Profissional \\
\hline Natureza do trabalho & Rotineiro & Especializado \\
\hline $\begin{array}{l}\text { Mecanismos de } \\
\text { coordenação }\end{array}$ & $\begin{array}{l}\text { Padronização do processo } \\
\text { de trabalho }\end{array}$ & $\begin{array}{l}\text { Padronização de } \\
\text { habilidades a partir de } \\
\text { treinamento e formação }\end{array}$ \\
\hline Fonte de autoridade & Controle gerencial & Conhecimento do trabalho \\
\hline Local da autoridade & Escala administrativa & $\begin{array}{l}\text { Os praticantes } \\
\text { profissionais }\end{array}$ \\
\hline $\begin{array}{l}\text { Responsabilidade na } \\
\text { execução }\end{array}$ & $\begin{array}{l}\text { Implementação sobre } \\
\text { diretrizes precisas }\end{array}$ & $\begin{array}{l}\text { Auto regulação: o campo } \\
\text { de especialistas estabelece } \\
\text { padrões; executores } \\
\text { exercitam o julgamento } \\
\text { dos padrões e a } \\
\text { discricionariedade a partir } \\
\text { dos padrões do campo. }\end{array}$ \\
\hline
\end{tabular}




\begin{tabular}{|l|l|l|}
\hline Dinâmica política & $\begin{array}{l}\text { Hierárquica, controle } \\
\text { estatal forte, fraco controle } \\
\text { dos executores }\end{array}$ & $\begin{array}{l}\text { Poderes de compensação: } \\
\text { especialistas e estado em } \\
\text { condições relativamente } \\
\text { iguais }\end{array}$ \\
\hline
\end{tabular}

Fonte: adaptado a partir de Mintzberg (1993).

Origens da Era Progressiva: o fascínio do modelo de fábrica

As origens desse arranjo um tanto peculiar encontram-se nas noções sobre ensino, administração e organização social do movimento conhecido como Era Progressiva. Em uma geração, entre 1890 e 1920, o sistema escolar moderno foi criado por um grupo de elites cívicas conhecidas como "administradores progressivos", que transformaram uma nação onde predominavam escolas de uma sala de aula, em uma nação com uma rede de sistemas escolares distritais. Influenciados pelos modelos tayloristas prevalecentes de organização empresarial, que buscavam usar ideias de gestão científica para controlar os trabalhadores e aumentar a eficiência, a maioria dos superintendentes, do sexo masculino, foi habilitada como CEOs para liderar os sistemas escolares, enquanto a maioria das professoras, em geral mulheres, deveriam seguir as regras e programas que seus superintendentes prescreviam. 0 treinamento para professores era relativamente pequeno e os professores não possuíam nenhum poder político para se opor às diretivas vindas de cima (TYACK, 1974; TYACK \& CUBAN, 1995).

Muitos dos nomes mais importantes nesse movimento provinham de departamentos e escolas de educação emergentes, os quais, em sua maioria, se colocavam com o aval dos administradores e não dos professores (CALLAHAN, 1962). Subjacente a esta visão estava a ideia de que a prática complexa carente de atenção na educação não era o ensino, mas a administração social. 0 presidente de Harvard, Charles Eliot, falando em nome do corpo docente, disse: “O corpo docente da Faculdade partilha com a maioria dos professores na Inglaterra e nos Estados Unidos pouco interesse ou confiança no que costuma ser chamado de pedagogia" (LAGEMANN, 2000, p. 63). O treinamento de administradores forneceu uma oportunidade para os departamentos de educação produzirem uma nova classe de profissionais especialistas, em sua maioria homens, cujo papel foi amplamente discutido como equivalente ao de um CEO. 0 desenvolvimento deste tipo de profissional permitiu que os departamentos de educação aspirassem à paridade com profissões como medicina, direito e engenharia e buscassem eliminar o 
estigma que veio com o treinamento de uma força de trabalho amplamente feminizada. Como Edward Cubberley descreveu em seu livro clássico de 1916, Public School Administration:

A supervisão escolar representa uma nova profissão que, com o tempo, terá um papel muito importante no desenvolvimento da vida americana. Em recompensas pecuniárias, sociais, profissionais e pessoais, se equipara às demais profissões eruditas, ao passo que a demanda por superintendentes de escolas municipais do tipo certo é hoje maior do que a procura por advogados, médicos ou ministros. As oportunidades oferecidas nesta nova profissão para homens de caráter forte, ampla simpatia, propósitos elevados, boa cultura, coragem, treinamento exato e habilidades executivas. . . hoje não se destacam em nenhuma das profissões, eruditas ou não. (pp. 130-131)

Cubberley (1916) sugeriu que se esperava que os superintendentes concluíssem a graduação e um ano de pós-graduação e que muitos continuassem com o doutorado, enquanto os professores precisavam apenas do ensino médio e de um programa de treinamento de dois anos. Para uma disciplina universitária que buscava ganhar terreno, o desenvolvimento de uma ciência da administração escolar que exigia treinamento extensivo de um corpo administrativo predominantemente masculino proporcionou um meio para os departamentos de educação e escolas reivindicarem equivalência com campos de status superior, como medicina e direito.

As preocupações centrais eram a organização da produção e do uso do conhecimento. Consistente com as divisões mencionadas entre pesquisadores universitários e professores, o que se desenvolveu foi um programa amplamente quantitativo e estatístico de pesquisa educacional realizado por cientistas da universidade, que o transmitiriam aos administradores escolares altamente treinados, que então o implementariam por meio de professores atuando na parte inferior do sistema. Esta abordagem hierárquica foi apresentada pelo especialista Edward Thorndike em seu texto de 1906 intitulado "Os Princípios de Ensino":

É problema das autoridades superiores das escolas decidir o que a escola deve tentar alcançar e fazer planos para o trabalho das escolas que atinjam os fins desejados. Tendo decidido quais mudanças devem ser feitas, eles confiam aos professores a tarefa de fazê-las. (citado em LAGEMANN, 2000, p. 60).

Este sistema permitiu que departamentos de educação fizessem mais pesquisas básicas e menos pesquisas aplicadas de maneira que espelhasse seus colegas de artes e 
ciências de maior prestígio; o que ela não fez foi produzir consistentemente o tipo de conhecimento prático sobre o ensino necessário para a área.

\section{0 caminho não percorrido: organizar-se como profissão}

Um modo alternativo de organização social mais profissional pode ter revertido uma série dessas suposições. John Dewey defendeu esse modelo, e o fracasso de seus esforços revela a força dos imperativos institucionais que puxam na direção oposta. $\mathrm{Na}$ famosa escola laboratório de Dewey, fundada enquanto ele estava na Universidade de Chicago, a própria escola serviu como uma oportunidade primária para a pesquisa. Nas palavras de Dewey (1896), uma escola laboratório deve suportar "A relação do trabalho em pedagogia que um laboratório tem com a biologia, a física, ou química" (p. 417). A pesquisa, na opinião de Dewey, deve ser realizada em escolas, em contraste com a visão de Thorndike de que o tempo gasto nas escolas foi em grande parte um "engodo" (LAGEMANN, 2000, p. 59). Além disso, Dewey não procurou dividir os papéis de pesquisador e professor, argumentando, em vez disso, que ambos estavam interessados no mesmo objetivo de melhorar a aprendizagem. Em vez de ter "um especialista ditando métodos educacionais e conteúdo para um corpo de professores receptores passivos", Dewey defendeu "a adoção de iniciativa intelectual, discussão e decisão com todo corpo escolar" (LAGEMANN, 2000, p. 50).

Nas ideias de Dewey evidenciava-se uma forma inicial do que poderia vir a ser a construção de uma profissão baseada no conhecimento prático: professores e pesquisadores trabalhando juntos para produzir novos conhecimentos; conhecimento que é organizado em parte em torno de questões práticas vindas do campo, e não inteiramente dos especialistas pesquisadores universitários; uma relação saudável e interdependente entre o conhecimento básico e aplicado; professores tratados como profissionais capazes de tomar "iniciativa intelectual" e organizar seu próprio trabalho, em vez de implementar as ideias de outros.

Mas ainda que suas ideias tenham sido amplamente discutidas, o modelo de pesquisa de Dewey como uma função compartilhada entre pesquisadores e professores foi rejeitada por departamentos de educação universitária, que buscavam se elevar justamente por se distanciarem dos professores. Como Ellen Lagemann (2000) argumenta: 
Sua posição estava muito em desacordo com a hierarquia que então se desenvolvia entre instituições educacionais, uma hierarquia em que a maioria dos pesquisadores universitários do sexo masculino geraria conhecimento educacional necessário para gestores escolares, em sua maioria também do sexo masculino, que, por sua vez, seriam responsáveis por ditar e supervisionar os métodos de ensino a serem utilizados pelos professores nas escolas, especialmente no ensino elementar, em que predominavam as mulheres (p. 51).

Essas decisões da Era Progressiva produziram o sistema que vemos hoje: pesquisadores universitários desenvolvendo conhecimentos que são mais úteis para o avanço das disciplinas das ciências sociais do que para tratar de problemas de prática; administradores que usam esse conhecimento como base para as políticas e programas que implementam; e professores resistindo ao que consideram ordens mal formuladas vindas de cima. Este sistema é consistente com nosso respeito pela ciência e o status mais elevado que atribuímos às universidades em relação às escolas de educação básica, mas tem sido fundamentalmente ineficaz porque busca resolver um problema de inadequação do conhecimento profissional e das habilidades necessárias ao processo de implementação e administração burocrático (MEHTA, 2013).

Finalmente, como ficou mais claro ao longo do século, a organização do campo como uma burocracia, e não como uma profissão afetou não apenas o núcleo de sua prática, mas também sua política, criando um Estado forte e uma classe de profissionais enfraquecida. Áreas estabelecidas como medicina e ensino superior se organizaram como guildas autorreguladas que eram as principais responsáveis por treinamento, licenciamento e definição de padrões contínuos de prática (JENCKS \& RIESMAN, 1968; Starr, 1982). Ao fazer isso, eles foram capazes de assumir um considerável controle sobre seus domínios. Em contraste, na educação básica, a ausência de tal organização profissional resultou em professores funcionando essencialmente como "burocratas de rua", responsáveis por implementar decisões de cima, em vez de especialistas respeitados cujas vozes são ouvidas.

\section{Longas sombras da era progressiva: Marcas organizacionais e dependência de trajetória}


Ao caracterizar os padrões de evolução histórica, os sociólogos observaram que frequentemente há marcas organizacionais deixadas pelas condições sob as quais as organizações são fundadas que criam um DNA organizacional razoavelmente estável, persistente mesmo quando as circunstâncias mudam (STINCHCOMBE, 1965). Em uma chave relacionada, os cientistas políticos argumentaram que frequentemente há um processo de "dependência de trajetória" em que as decisões iniciais (por exemplo, organizar a saúde como um bem público ou um mercado privado) afetam eventos subsequentes, criando as normas, estruturas e distribuição de poder que, por sua vez, moldam as decisões e ações posteriores (HACKER, 1998; PIERSON, 2000). No caso da educação americana, podemos ver estas marcas como a formação de identidades organizacionais de atores-chave no setor de educação e a dependência de trajetórias como o padrão de interação entre esses atores que se desenvolveu ao longo do tempo para produzir os resultados que vemos.

Com respeito às marcas organizacionais, examino o impacto da organização burocrática do setor educacional em três direções: organizações / sindicatos de professores (os profissionais), escolas de formação de professores (os produtores de conhecimento) e funcionários distritais / estaduais / federais (o Estado). Os professores organizaram-se inicialmente em associações fracas (que incluíam administradores, bem como professores) que lhes dava pouco poder em relação aos superintendentes e conselhos escolares. Os professores recebiam o que quer que os conselhos locais decidissem pagar e tinham pouco a dizer sobre as suas condições de trabalho. A partir do início dos anos 1960, à medida que mais homens ingressaram no ensino e as mudanças legais apoiavam a organização dos funcionários do setor público, os professores começaram a se organizar de acordo com o modelo sindical que vemos hoje. Nesse modelo, os representantes dos professores, como nos sindicatos de operários, defendiam o aumento dos salários e protegiam os trabalhadores de decisões caprichosas dos administradores, mas recusavam a responsabilidade pelos resultados escolares ou pela governança, que eram considerados trabalho de gestão. Esta foi uma resposta sensata dada o posicionamento inicial dos professores como atores fracos na base da escada da implementação de políticas que, na ausência de uma organização sindical forte, receberiam ainda menos e teriam ainda menos controle sobre seu trabalho.

Ao mesmo tempo, essa resposta teve custos consideráveis. Ao se organizarem como sindicatos de negócios, os professores limitaram fundamentalmente sua 
responsabilidade e controle sobre a qualidade de seu trabalho. Políticas que parecem sensatas do ponto de vista sindical - limitar as horas de trabalho, proteger os membros de demissões, definir escalas salariais - são frequentemente vistas como um obstáculo à melhoria da qualidade da escola, porque a proteção dos direitos dos trabalhadores pode obstaculizar decisões sobre o que seria melhor para escolas e alunos (MOE, 2011). Essa forma de posicionar os professores compromete sua credibilidade como atores políticos (MEHTA \& WINSHIP, 2010).

Reconhecendo essa dinâmica em meio a uma crise de qualidade escolar em meados da década de 1980, o presidente da American Federation of Teachers (AFT), Albert Shanker, argumentou que os sindicatos precisavam seguir uma direção mais profissional se quisessem ser atores políticos legítimos. "Reformar ou ser reformado", argumentou ele, e os esforços de Shanker e de outros produziram uma série de iniciativas que buscavam mover os sindicatos em uma direção mais profissional. Um grupo de base local, conhecido como Teacher Union Reform Network (TURN), procurou reformular-se explicitamente de acordo com o que eles chamaram de "sindicalismo profissional" (KAHLENBERG, 2007). 0 objetivo era unir questões básicas em torno de salários e condições de trabalho com questões focadas na qualidade da prática pedagógica, incluindo a criação de padrões para o ensino, assistência e revisão de pares e, em alguns casos, tendo professores exercendo gestão conjunta de escolas com administradores e responsabilização pelos resultados. 0 sindicalismo profissional, no entanto, enfrentou uma luta difícil: após mais de vinte anos de esforço, há menos de duas dúzias de organizações locais filiadas à TURN. Particularmente à medida que as pressões externas por responsabilização e até mesmo a quebra de sindicatos aumentaram, passa a ser difícil para os líderes sindicais vencer as eleições sem prometer defender vigorosamente os direitos dos professores conforme tradicionalmente definidos. Como prevê a teoria de dependência de trajetória, os sindicatos de professores foram criados para proteger os direitos de seus filiados em um contexto anterior específico, e os esforços para reformulálos para servir a funções mais profissionais em nosso contexto atual foram difíceis de vender (KERCHNER, KOPPICH E WEERES, 1997; MOE, 2011; TOCH, 1991).

Há uma história paralela sobre as escolas de formação, tanto no que diz respeito à produção de conhecimento quanto à formação de professores. Faculdades de Educação assumiram sua forma moderna na Era Progressiva, quando mudaram de seu interesse anterior como disciplina do campo da filosofia para as ciências sociais emergentes. Tal 
como acontece com outras escolas profissionais, as faculdades de educação tinham, em teoria, uma responsabilidade dupla para com a academia e, para o campo mais amplo, e eram encarregados de produzir conhecimento que fosse respeitado pelos estudiosos, bem como adequado para o treinamento de profissionais. Mas uma série de fatores frustrou a capacidade das faculdades de educação cumprirem plenamente essa missão dupla. 0 fator mais importante foi que as Faculdades de educação se alinharam com as normas da academia: contratando pesquisadores com doutorado, publicando em periódicos acadêmicos e se orientando para o desenvolvimento de conhecimento e teoria científica social cada vez mais refinados (CLIFFORD \& GUTHRIE, 1988). As faculdades de educação mais seletivas evoluíram enfatizando a formação de administradores sobre a formação de professores. Em contraste com outros campos, a liderança da formação não buscava treinar aqueles que realmente trabalhariam no campo; essa função foi deixada principalmente para escolas menos exclusivas. Geralmente, a formação de professores tem sido amplamente criticada por sua ênfase na teoria sobre a prática, talvez não surpreendentemente, uma vez que os professores responsáveis por ela geralmente são treinados como acadêmicos e não recrutados por sua experiência pedagógica (LANIER \& LITTLE, 1986; LEVINE, 2006).

0 incentivo à reforma escolar na década de oitenta levou a um esforço por mudanças significativas. Um consórcio de quase uma centena de universidades importantes se reuniu com o objetivo de transformar seus programas de formação de professores para torná-los mais relevantes para a prática. 0 Holmes Group, batizado em homenagem ao ex-reitor da Harvard Graduate School of Education Henry Holmes, publicou uma série de relatórios criticando os problemas com a formação de professores existentes até então. Os relatórios propunham que houvesse vínculos mais estreitos com a prática, especialmente na forma de escolas de desenvolvimento profissional que também poderiam servir como locais para formação de professores e como laboratórios de pesquisa. Quase trinta anos depois, as análises do trabalho do Holmes Group sugerem novamente o poder duradouro do modelo inicial. Apesar de ter o compromisso de várias importantes faculdades de educação, financiamento significativo de fundações e três relatórios amplamente citados, quando o Grupo Holmes realmente se voltou para a reforma, ele fracassou. Como uma autópsia descreveu 
Dez anos após a publicação de Tomorrow's Teachers, o currículo de formação de professores em programas nos Estados Unidos mudou pouco, poucas universidades apoiaram escolas de desenvolvimento profissional ou outras colaborações próximas com escolas da educação infantil ao ensino médio (K-12) e o sistema tradicional de licenciamento de professores ficou intacto. (FORZANI, 2011, p. 10)

As razões para essa resistência à mudança foram novamente consistentes com o desenho organizacional. As análises retrospectivas sugeriram que o corpo docente de Faculdades de educação seletivas não tinha inclinação ou know-how para ensinar pedagogia, ressentiu-se da mudança em direção à pesquisa prática de questões mais amplas de pesquisa científica social e abraçou normas de liberdade acadêmica e autonomia em oposição a ideia de um programa de formação controlado. Por sua vez, os distritos escolares não estavam ansiosos para entregar suas escolas às universidades e tinham pouca experiência ou interesse no tipo de co-design de tal projeto exigiria. Os esforços para criar novas escolas de desenvolvimento profissional mais integradas que iriam transpor as fronteiras existentes entre profissionais e pesquisadores foram frustrados pelos papéis e padrões existentes que se desenvolveram no setor desde a Era Progressiva (FORZANI, 2011; FULLAN, GALLUZZO, MORRIS, \& WATSON, 1998).

Por sua vez, as políticas distritais, estaduais e federais se desenvolveram de maneiras que também são consistentes com a forma como essas agências governamentais desenvolveram inicialmente suas funções. Na ausência do tipo de poderes de compensação que existem na medicina, na academia ou em outras profissões mais desenvolvidas, os funcionários sentem-se bastante livres para desenvolver programas, requisitos e outras regras que devem ser implementados pelos professores para o benefício dos alunos. Esta conformidade orientada teve alguns benefícios, especialmente no caso de proteger os direitos dos alunos. Por exemplo, o uso de políticas do governo tem sido inquestionavelmente benéfico para garantir os direitos de minorias, acesso justo aos serviços para alunos com deficiência e instrução apropriada para alunos que não tem inglês como segunda língua.

Mas o que tem sido mais difícil foi empregar essa mesma ferramenta não apenas para estabelecer pisos, mas também para mover em direção aos tetos - não apenas para evitar danos, mas também para produzir escolaridade de qualidade (WISE, 1979). Como David Cohen e Susan Moffitt (2009) argumentam, nos anos desde a aprovação do Ato de Educação Primária e Secundária (Elementary and Secondary Education Act) em 1965, as 
ambições para o que deve ser alcançado aumentaram substancialmente, mas o que o governo pode realmente fazer usando suas alavancas permaneceu basicamente o mesmo. 0 resultado foi uma considerável lacuna entre o que o governo procura fazer e o que pode realmente realizar, em grande parte porque ferramentas como a criação de padrões, avaliações e prestação de contas à distância fazem pouco para construir a experiência necessária para atingir as metas desejadas.

Se colocarmos essas três histórias em movimento e integrá-las podemos ter uma imagem mais clara de como chegamos onde estamos hoje. Durante seu primeiro meio século (aproximadamente 1910-1960), o sistema que os progressistas criaram funcionou de forma um tanto harmoniosa, porque as expectativas sobre o que as escolas precisavam produzir eram bastante limitadas. Uma ligação frágil preservou a autonomia do professor o suficiente para fazê-los sentirem que estavam no controle de seu próprio domínio, enquanto os conselhos escolares e superintendentes tinham poder formal suficiente para preservar a ideia de um sistema de supervisão e controle democrático. As Faculdades de educação treinavam administradores e professores, uma função que pagava suas contas enquanto permitia que seus professores pesquisassem o que gostassem. Os professores, em sua maioria mulheres com poucas opções de emprego e que, frequentemente, não eram a fonte principal de renda de suas famílias e, portanto, seu baixo salário não gerava resistência significativa. Em 1960, a maioria dos alunos brancos se formava no ensino médio, o que, independentemente de quanto tivessem realmente aprendido, os certificaria para ocupações de classe média na indústria e em outros empregos. Um número menor de crianças mais favorecidas foi para melhores escolas públicas ou privadas e depois para a universidade. 0 resultado foi que muitos atores diferentes conseguiram o que precisavam, mesmo que o setor como um todo não estivesse fazendo muito para maximizar o aprendizado de todos os seus alunos (MEYER \& ROWAN, 1977).

À medida que as expectativas de escolaridade aumentaram nos últimos cinquenta anos, os limites dessa forma de construir o setor tornam-se cada vez mais evidentes. Impulsionados por uma combinação de imperativos de direitos civis e a mudança econômica de uma economia industrial para uma pós-industrial, os formuladores de políticas agora esperam que todos os estudantes possam atingir níveis acadêmicos bastante elevados. Mas as formas como essas metas foram perseguidas dizem mais sobre os caminhos pré-estabelecidos em que esses atores estão operando, do que sobre como o setor precisaria ser construído para produzir tais resultados. Os formuladores de políticas 
e outros atores externos, sentados no topo de burocracias hierárquicas, fracamente conectados às escolas, têm procurado estreitar esta conexão e aumentar a pressão por desempenho, usando as alavancas que têm à sua disposição - em grande parte padronização, avaliação e responsabilização. Os professores, por meio de seus sindicatos, têm resistido em grande parte aos apelos por responsabilização externa, alegando que tais exigências diminuem sua autonomia profissional e os culpam injustamente por fatores fora de seu controle. Tal postura apenas fortalece o desejo dos formuladores de políticas por responsabilização, o que, por sua vez, só aumenta o ressentimento dos profissionais em relação aos formuladores de políticas. Enquanto isso, a maior parte das faculdades de educação continuaram praticamente inalteradas: não sendo realmente responsáveis por produzir conhecimento que possa orientar de forma viável o trabalho para melhores resultados. Além disso, as oportunidades profissionais ampliadas para as mulheres contribuíram para a perda de mão de obra cativa em campo e, portanto, para enfrentar o desafio crescente de recrutar profissionais talentosos para suas fileiras. Dito isso, o resultado é que continuamos a perseguir o desafio da qualidade por meio de mecanismos regulatórios limitados, evitando o problema central de atrair o capital humano necessário, construir a base de conhecimento, e criar estruturas para usar esse conhecimento que podem, em combinação, realmente produzir melhores resultados em escala. Como prevê a dependência de trajetória, nossas decisões são compreensíveis à luz de nossa história, mas não bem adaptadas às nossas necessidades atuais.

Esses desafios tornaram-se particularmente urgentes à medida que o campo busca avançar em direção a uma instrução mais ambiciosa, ou "aprendizado mais profundo", para todos os seus alunos. A pesquisa sugere consistentemente que o padrão dominante na instrução americana ao longo do século passado tem sido pedir aos alunos que respondam perguntas fechadas, de aplicar e relembrar, que ficam na base das taxonomias de aprendizagem tradicionais (COHEN, 1988; CUBAN, 1984; ELMORE, 1996; GOODLAD, 1984). Descobertas recentes do Measures of Effective Teaching Project (2012) sugerem que esses padrões persistem, em milhares de salas de aula que compuseram a amostra da pesquisa, eles descobriram que mais de 60 por cento das aulas eram administradas com competência, mas que apenas uma em cinco apresentava instrução ambiciosa que pedisse aos alunos que raciocinassem e respondessem a perguntas mais abertas. Quanto mais pedimos aos professores para envolver os alunos no tipo de pensamento crítico e 
raciocínio que é a base da vida do século XXI, mais imperativo se torna ter um corpo docente especializado, ele próprio preparado para este tipo de trabalho.

\section{Expirais descendentes: Consequências da fraca profissionalização no campo}

A forma do setor como uma burocracia hierárquica, em vez de uma profissão desenvolvida, teve um conjunto variado de implicações para a educação hoje. Em particular, contribuiu para uma relação doentia entre a prática educacional dentro das escolas e as forças externas que buscam moldar essa prática. 0 resultado tem sido o antagonismo e a desconfiança entre os formuladores de políticas e os praticantes, com poucas melhorias esperadas na prática em escala.

Um bom lugar para começar é a ausência de uma base de conhecimento compartilhada e codificada de forma consistente e de uma infraestrutura profissional de acompanhamento que oriente o trabalho em outras áreas (COHEN, 2011). Grande parte do que define os profissionais é a expectativa de que eles lidem com o trabalho rotineiro de forma relativamente consistente com os padrões de suas respectivas áreas. É por isso que selecionamos um profissional qualificado para consertar um cotovelo quebrado, pousar um avião ou fazer um testamento. Na ausência de tais padrões, o ensino desenvolveu um ethos de profissionalismo defensivo que enfatiza a autonomia individual

- "Eu sou um profissional e, portanto, devo fazer exatamente o que acho que é certo" - ao invés do profissionalismo mais maduro de outros campos, nos quais o conhecimento especializado compartilhado estabelece a base para a prática (LORTIE, 1975). Profissionais em áreas mais maduras, como medicina, exercem seu julgamento e discricionariedade individual, mas o fazem no contexto da aplicação de uma base de conhecimento comum a situações específicas. A educação, em contraste, evoluiu em torno de um etos de "todos os professores precisam inventar boas práticas para si mesmos", que, na ausência de construir e contribuir para uma base de conhecimento pública compartilhada, é contraproducente para os esforços de criar qualidade em escala (MEHTA, GOMEZ, \& BRYK, 2012).

Os professores protegem sua autonomia dessa maneira precisamente porque são frequentemente bombardeados com diretrizes externas de pouca utilidade prática imediata. Os professores estão na base de uma hierarquia administrativa e têm de fazer o que seus superiores ordenam, independentemente de o que está prescrito ser bem 
pensado ou adequado às suas circunstâncias particulares. Além disso, na ausência de uma base de conhecimento bem desenvolvida para orientar a prática, o setor atrai provedores que oferecem "planos de dez pontos" para alcançar seus resultados educacionais preferidos; ele também oscila descontroladamente entre os extremos em sua abordagem ao ensino de disciplinas essenciais, como leitura e matemática. Em campos como o direito e a medicina, nos quais o desenvolvimento profissional é feito quase exclusivamente por membros da profissão, uma linguagem técnica compartilhada permite que tal desenvolvimento seja adicionado ao conhecimento existente, e os profissionais têm alguma escolha sobre o que desejam aprender mais. Em contraste, na educação, os professores são frequentemente enviados para programas escolhidos pelo diretor ou distrito, onde o desenvolvimento profissional é frequentemente oferecido por não professores e onde as ideias parecem circular sem fim, com pouca conexão com uma base de conhecimento existente. Não é de surpreender que as avaliações do desenvolvimento profissional em educação tenham sugerido que esses programas raramente têm um impacto perceptível na prática (HILL, 2007).

Uma consequência relacionada à ausência de uma profissão forte é que a educação é jogada como uma bola de futebol política. Uma razão pela qual é difícil montar campanhas de melhoria sustentada na educação é o que vários observadores apelidaram de fenômeno das "rodas giratórias": superintendentes e programas circulam rapidamente, conforme um conjunto de idéias plausíveis dá lugar a outro, e as idéias são frequentemente introduzido antes que os mais velhos tenham uma chance real de trabalhar (HESS, 1998; PAYNE, 2008). Mas comparações internacionais de sistemas de educação mais profissionalizados sugerem que esse tipo de circulação não é uma característica necessária da reforma escolar no domínio público. Embora seja apropriado que a política apareça na escola pública, em países com profissões educacionais e ministérios mais fortes, a contribuição do público é combinada com a experiência profissional para produzir melhores resultados e campanhas mais sustentadas para melhoria (OCDE, 2010).

0 resultado na educação americana é uma espiral descendente de profissionais e formuladores de políticas. Do ponto de vista dos professores, os formuladores de políticas e administradores distritais geralmente não têm contato com a realidade da sala de aula; eles pulam de uma prioridade para outra por razões amplamente políticas e exercem o poder de maneira injusta, apesar de seu conhecimento útil limitado. Livros populares na 
literatura de professores, como Weapons of Mass Instruction (GATTO, 2009), comparam a política a uma guerra contra alunos e professores. Professores experientes frequentemente expressam cinismo compreensível sobre os ciclos e os modismos de superintendente. Por outro lado, da perspectiva dos administradores e formuladores de políticas, parece irresponsável não tentar intervir quando eles confrontam as evidências sobre a ampla variação na habilidade de professores nas salas de aula e o baixo desempenho dos alunos, especialmente alunos pobres e pertencentes a minorias. Então, eles intervêm, começando a espiral descendente novamente.

\section{Espirais ascendentes: como remontar o setor e profissionalizar o campo}

O que o sistema educacional americano precisa é o oposto da dinâmica descrita acima; precisa de uma espiral ascendente na qual o interno e o externo sejam vistos mais como parceiros do que adversários. Os níveis iniciais de habilidade profissional e especialização nas escolas criam um terreno mais fértil para experimentar novas ideias. Essas ideias são então oferecidas menos com o espírito de conformidade e mais com o espírito de fornecer novos conhecimentos que podem ser bem adequados para resolver problemas da prática. Ambas as partes aceitam que a outra está operando de boa fé e pode ter algo valioso para contribuir com o processo, criando assim uma cultura de respeito entre as partes que está totalmente ausente na educação americana. 0 poder externo, nesses casos, muitas vezes não é apenas parte do estado, mas também parte da profissão; portanto, tem mais conhecimento sobre a prática educacional e é mais capaz de manter a consistência ao longo do tempo, reduzindo o tipo de oscilação da moda entre os extremos que é característico da escolaridade americana. Ao criar uma orientação profissional, em vez de burocrática, poderíamos escapar da espiral descendente em que estivemos e avançar em direção ao tipo de espiral ascendente que é característica das nações de alto desempenho.

Pesquisas comparativas entre países no âmbito do Programa Internacional de Avaliação de Alunos (PISA) ainda estão em seus estágios iniciais, mas há evidências preliminares de que vários países de alto desempenho organizam seu trabalho educacional de uma forma que é relativamente semelhante ao de profissões mais fortes nos Estados Unidos. Países tão variados como Cingapura, Finlândia, Coréia e Canadá tomam algumas medidas semelhantes na organização de seus setores educacionais: eles 
recrutam seus professores do terço superior de suas coortes de faculdades, dão-lhes treinamento extensivo e altamente prático, apoiam suas escolas com fortes estados de bem-estar, e então dependem mais da responsabilidade profissional interna do que da responsabilidade leiga externa para produzir resultados. 0 Estado desempenha um papel importante nesses processos, mas os ministérios da educação que dirigem os sistemas em países líderes nos resultados do PISA contam com profissionais de educação como parte dos governos, o que significa que seu papel é menos de monitorar e punir escolas e muito mais de trabalhar com eles em um processo de aprimoramento profissional compartilhado. Ao fazer isso, eles também procuram criar níveis de confiança, legitimidade e respeito entre os atores em diferentes níveis do sistema que estão totalmente ausentes nos Estados Unidos (DARLING-HAMMOND, 2010; LEVIN, 2008; OECD, 2010)

Não existem dois países totalmente iguais, e seria um erro presumir que estratégias que funcionaram em outros contextos podem simplesmente ser importadas no atacado para os Estados Unidos. Embora esses países sejam diferentes uns dos outros, nenhum deles compartilha a história racial conturbada da América, seu ceticismo em relação ao governo e seu tamanho e diversidade de pontos de vista e opiniões. Estruturalmente, os Estados Unidos também têm uma estrutura mais descentralizada do que muitas dessas outras nações, o que significa que o locus de ação é distribuído por mais atores. Ainda assim, por mais que seja um erro pensar que estratégias externas podem ser importadas sem crítica, seria igualmente provinciano pensar que não temos nada a aprender com o resto do mundo. Também é impressionante que a imagem que surge nesses países pareça relativamente semelhante em seus atributos essenciais aos das profissões mais fortes dentro dos Estados Unidos.

Mesmo com as diferenças de contexto, existem maneiras de os Estados Unidos agirem para transformar seu setor de educação em uma direção mais profissional. Existem quatro aspectos inter-relacionados às mudanças necessárias que correspondem às quatro funções centrais em qualquer campo. Precisamos fazer mudanças na rota de formação de capital humano, mudanças na base de conhecimento, mudanças na organização dos processos que garantem a utilização do conhecimento e mudanças no papel dos distritos e do estado, de monitores de implementação de políticas para parceiros nos processos de melhoria social. Nenhuma dessas coisas será fácil, mas todas são necessárias se o objetivo for a melhoria de todo o setor. 


\section{Construir uma força de trabalho de profissionais}

Com relação ao capital humano, precisamos levar a sério toda a cadeia de eventos: atrair, selecionar, treinar e reter nossa próxima geração de professores. 0 foco atual na avaliação de professores serve apenas para classificar nossos professores existentes; não faremos progresso no longo prazo sem uma estratégia que aborde todos os aspectos do processo. 0 objetivo deve ser padrões muito mais elevados para o ingresso em programas de formação de professores e padrões mais elevados para o credenciamento para o ensino. Subjacente a esta abordagem está o compromisso de se tornar mais seletivo sobre quem pode se tornar um professor. 0 objetivo não é necessariamente selecionar professores simplesmente com notas mais altas nos testes; com o tempo, esperamos que um sistema muito mais refinado possa ser desenvolvido, aumentando nosso poder de previsão sobre quem provavelmente se tornará um bom professor. Padrões mais altos causarão escassez inicialmente, mas será fundamental manter a linha se o objetivo for sinalizar que ensinar é uma profissão séria.

As estrelas podem estar convergindo para criar algum progresso neste ponto. No ano passado, a American Federation of Teachers (2012), a National Education Association (2012) e o Council of Chief State School Officers (2012) publicaram, cada um, um importante relatório pedindo a elevação dos padrões de entrada para os professores iniciantes. A proposta da AFT é a que mais chama a atenção, pois preconiza um "exame da ordem" para um ensino semelhante ao que existe em direito, medicina e outros campos desenvolvidos. Este é um conjunto de desenvolvimentos muito promissor porque coloca os sindicatos diretamente à frente de uma agenda para elevar os padrões para toda a profissão docente, em vez de proteger seus membros menos competentes. No longo prazo, tal exame pode ser o ponto de partida para um ciclo mais virtuoso: se o público for persuadido de que membros titulares da profissão demonstraram sua capacidade de ensinar, então o respeito pela profissão aumentará, o que pode eventualmente levar a salários mais altos, o que, com a combinação de status e dinheiro, tornaria mais fácil atrair candidatos mais fortes no futuro.

Um conjunto integrado de mudanças é necessário no treinamento de professores. A explosão de um pluralismo de diferentes provedores de formação de professores nos últimos vinte anos - incluindo programas alternativos de certificação, residências de 
professores em áreas urbanas e programas de treinamento de professores administrados pelas próprias escolas - expandiu muito a gama de experimentação sobre como treinar novos professores. A pesquisa inicial sugere que há uma variação muito maior dentro desses tipos do que entre eles, mas os programas específicos que funcionam bem, têm um conjunto não surpreendente de elementos comuns. Todos os programas bem-sucedidos tendem a selecionar pessoas com treinamento de conteúdo no que vão ensinar, dar-lhes prática cuidadosa e extensa e feedback sobre seu trabalho nas escolas, e ensiná-los a usar dados e refletir cuidadosamente sobre sua prática. A política deve continuar a abraçar o pluralismo de diferentes tipos de instituições de treinamento; mas como padrões mais claro, alguns sobreviverão e outros não, com base no fato de seus graduados serem consistentemente capazes de passar em exames e se tornarem professores.

A formação de professores inspira-se na medicina e desenvolver um programa de aprendizagem semelhante ao sistema de residência médica. Atualmente, as instituições de formação de professores são responsáveis pela preparação dos professores durante o ensino dos alunos ou no primeiro ano de ensino, e os distritos são responsáveis pela introdução depois disso. Faria mais sentido unir essas funções em instituições únicas que supervisionariam o desenvolvimento dos professores durante seus primeiros três anos de ensino. Professores experientes seriam responsáveis por este treinamento e precisariam ter tempo suficiente embutido em suas agendas (semelhante aos médicos atendentes de hospitais) para supervisionar os novos professores.

Os novos professores receberiam níveis maiores de responsabilidade ao longo do tempo, começando com o ensino em equipe com professores mestres. Em seguida, eles ensinariam uma carga parcial (uma aula para professores do ensino fundamental e médio e parte do dia para professores do ensino fundamental) e usariam o resto do tempo para feedback, reflexão e integração do que estão aprendendo sobre o ensino com suas experiências em sala de aula. Ao longo do segundo e terceiro anos, eles assumiriam responsabilidade crescente por mais prática em sala de aula, proporcional com suas habilidades e competências em desenvolvimento. Os programas de residência de professores, como a Residência de Professores de Boston, desenvolveram recentemente escolas de "clínicas de ensino" que tentam seguir nessa direção. A criação de um processo de treinamento de professores supervisionado de perto prepararia bem as pessoas para demonstrar as habilidades de ensino necessárias para se tornarem professores efetivos (MEHTA \& DOCTOR, 2013). 


\section{Codificando uma Base de Conhecimento}

Mudar quem se torna professor e como eles são treinados terá pouca importância se não houver uma base de conhecimento compartilhada e examinada publicamente que fundamenta esse treinamento. Em sua essência, as profissões se apoiam em suas respectivas bases de conhecimento. Na ausência de perícia especializada, não há fundamento para o pedido de licenciamento profissional. A pesquisa sugere que existem três tipos de conhecimento mais relevantes para o ensino em sala de aula: conhecimento do conteúdo sobre o assunto, conhecimento pedagógico sobre como ensinar e conteúdo pedagógico sobre como ensinar assuntos específicos (SHULMAN, 1987). Os professores experientes não apenas possuem esses conhecimentos, mas também sabem como integrá-los em situações reais; como especialistas em outros domínios, eles são capazes de diagnosticar situações rapidamente e recorrer a um amplo repertório de técnicas de resposta (CHI, GLASER, \& FARR, 1988; CIMINO, 1999; LIVINGSTON \& BORKO, 1989). 0 bom ensino também tem uma dimensão afetiva, pois a capacidade de desenvolver um relacionamento afetuoso, mas exigente com os alunos é crítica para o sucesso (GROSSMAN \& MCDONALD, 2008).

Desenvolver uma base de conhecimento que possa contemplar um campo complexo, interativo, dependente do contexto e com conflitos de valor não é fácil. É improvável que tome a forma clínica, relativamente livre de decisões que vemos na medicina (ou seja, na presença dos sintomas X, Y e Z, solicitamos o teste A, que nos ajudará a diferenciar entre o tratamento $B$ e o tratamento $C$ ), porque as demandas em tempo real são muito grandes e o impacto de qualquer decisão depende muito do contexto (por exemplo, é diferente ensinar sobre conflitos sobre ônibus em Boston do que ensinar o mesmo tópico no Mississippi). Mas o que uma base de conhecimento pode fazer é informar, em vez de orientar as decisões; poderíamos saber muito mais sobre como professores especialistas criam bons climas em suas salas de aula, sobre quais tipos de estruturas e apoios os alunos precisam ao empreender investigações históricas e sobre como ajudar os alunos a se moverem em direção a uma maior proficiência oral em línguas. Esse conhecimento pode ir desde micro questões sobre movimentos do professor até questões mais amplas sobre a melhor forma de estruturar unidades ou sequências de unidades para alcançar um entendimento cada vez mais profundo. 
No contexto dos EUA, o maior desafio neste domínio é que não existe uma entidade encarregada especificamente de produzir o conhecimento de que precisamos. Na maioria das vezes, os pesquisadores publicam para outros pesquisadores; os professores desenvolvem conhecimento prático, mas não são apoiados para avaliá-lo regularmente ou compartilhar publicamente tal conhecimento verificado; e os planejadores de currículo comercial produzem o que os distritos e estados comprarão sem consideração substantiva pelo que produziria uma prática educacional de alta qualidade (HIEBERT, GALLIMORE E STIGLER, 2002). Ao mesmo tempo, existem muitos bolsões promissores, incluindo redes charter produzindo seu próprio conhecimento sobre ensino, plataformas de Internet que permitem aos professores compartilhar aulas, esforços do Teach for America para codificar o que descobriu ser eficaz para seus membros principais, pesquisadores independentes como Jon Saphier (2008) e seu trabalho em The Skillful Teacher, e, claro, alguns pesquisadores que estão particularmente interessados na prática pedagógica (CHARLOT, TRAN, \& STEMM-CALDERON, 2013). Com um empurrão do governo ou do setor filantrópico, é possível imaginar a educação passando por um processo semelhante ao que a medicina passou há um século, onde as fontes existentes de conhecimento se tornam mais integradas, examinadas e compartilhadas. Também seria útil construir um equivalente educacional ao National Institutes of Health, porque se o objetivo é ter uma comunidade de pesquisadores em tempo integral devotada explicitamente à produção de conhecimento relevante para a prática, então ter um grande compromisso público com essa tarefa é preciso.

\section{Colocando Conhecimento em Prática}

Desenvolver pessoas e conhecimento não ajudará muito se não houver maneiras consistentes de colocar o conhecimento em prática nas escolas reais. Colocando de outra forma, o treinamento por si só é uma alavanca fraca para fazer cumprir as normas de boas práticas, porque essas normas precisam ser reforçadas pelas rotinas diárias do trabalho real. As escolas fizeram algum progresso nessa questão nos últimos vinte anos, no maior uso de dados e na criação de comunidades de aprendizagem profissional. 0 próximo passo seria integrar ainda mais esses esforços à base de conhecimento da profissão em geral. Podemos imaginar um mundo onde a relação de alguém com o conhecimento varia de acordo com seu nível de especialização. Os professores iniciantes receberiam grandes doses de treinamento contínuo de professores mestres em suas escolas; os professores 
intermediários trabalhariam uns com os outros para aproveitar a base de conhecimento e adaptá-la a seus alunos e ideias particulares; e professores avançados desenvolveriam novas unidades e ideias em colaboração com pesquisadores para adicionar ao estoque de conhecimento do campo.

Finalmente, precisamos mudar a relação entre escolas, distritos e estados de uma cultura de desconfiança e obediência para uma cultura de respeito mútuo e aprendizado profissional. Os exemplos de outros países mostram que as escolas e os níveis mais altos de governo podem trabalhar em conjunto, com a questão nesses sistemas menos sobre quem controla o quê e mais sobre como as diferentes partes podem contribuir de maneiras diferentes para resultados compartilhados. Nos Estados Unidos, essa mudança cultural seria tanto causa quanto consequência das outras mudanças em uma estratégia de profissionalização. Se a profissão fosse mais bem informada e organizada internamente, conquistaria mais respeito daqueles que estão em posição superior no sistema; por sua vez, se os que ocupam posições mais altas no sistema demonstrassem mais respeito pela profissão, haveria mais espaço para os profissionais experimentarem crescerem e seria mais fácil atrair pessoas talentosas para a área.

\section{0 caminho até lá}

Um dos desafios da análise histórica é que ela parece promover o sentido fatalista de que a história é o destino. As instituições organizadas para fazer um tipo de coisa dificilmente farão outra: os sindicatos protegem seus membros, os distritos promulgam regras, os pesquisadores universitários escrevem principalmente para outros pesquisadores universitários. É muito mais fácil descrever a aparência de um tipo diferente de sistema do que explicar como podemos ir daqui para lá.

Ao mesmo tempo, vale lembrar que as instituições não são monolíticas e muitas vezes possuem vertentes que podem ser mobilizadas para a mudança. Os sindicatos de professores podem e têm apoiado elementos de uma agenda de profissionalismo, incluindo padrões mais elevados para professores ingressantes, processos de indução mais extensos para novos professores, assistência de colegas e programas de revisão por meio dos quais os professores orientam e avaliam seus colegas professores e planos de carreira que diferenciam as funções dos professores em diferentes níveis de habilidade e experiência. Distritos com visão de longo prazo, como Montgomery County, Maryland, e Long Beach, Califórnia, mostraram a maneira pela qual padrões cuidadosamente 
desenvolvidos, extensa capacitação para professores e a criação de relacionamentos respeitosos entre sindicatos e administradores distritais podem produzir paz de trabalho sustentada e melhorar gradualmente os resultados dos alunos (CHILDRESS ET AL., 2009; AUSTIN, SCHWARTZ, \& SUESSE, 2004). Em uma linha diferente, distritos "portfolios" como Nova Orleans, Nova York, Baltimore e outros mostraram o poder de devolver autoridade muito maior a escolas individuais, capacitando educadores locais e mudando o papel do distrito de seu comando e controle. Enquanto isso, tem havido um reconhecimento crescente por parte dos principais pesquisadores da importância das colaborações de prática universitária, levando à criação de instituições intersticiais como o Chicago Consortium on School Research e a Strategic Education Research Partnership, entidades de pesquisa que são diretamente orientadas para as necessidades da política e da prática. A maior agência de credenciamento de escolas de educação tradicional recentemente tornou a inclusão de um foco maior na prática uma parte importante dos requisitos de formação de professores.

Se as instituições existentes não podem se transformar de maneira útil, elas podem ser desafiadas ou mesmo substituídas por novas que sejam mais bem adaptadas às necessidades da época. Grupos como Teach Plus e Educators For Excellence são organizações relativamente novas que procuram representar professores fora dos sindicatos, defendendo políticas que se baseiam nos pontos fortes de professores qualificados para melhorar os resultados para os alunos. Programas de residência de professores e instituições de formação de professores regulares são novos participantes no mercado de preparação de professores que estão muito mais explicitamente focados na preparação de professores para a prática do que os programas universitários que procuram substituir. As organizações de gerenciamento de licenças, desde as pedagogicamente tradicionais, como Uncommon Schools, até as progressistas, como High Tech High, estão desenvolvendo conhecimento a partir da prática de seus principais professores e buscando incorporá-lo em seus programas de treinamento de professores. Em todas essas frentes, as instituições tradicionais estão enfrentando desafios externos, que atualmente são modestos em escala, mas cujos o papel pode aumentar se eles se mostrarem mais bem-sucedidos do que aqueles que procuram suplantar (MEHTA \& TELES, 2011).

Existem também desenvolvimentos externos que estão movendo os diversos atores na direção aqui defendida. A combinação dos padrões mais elevados defendidos 
pelos Common Core State Standards e o fato de que No Child Left Behind foi incapaz de realizar seus objetivos mais modestos levou a um maior interesse em aumentar as habilidades e conhecimentos dos professores, se quisermos atingir nossos objetivos cada vez mais ambiciosos. 0 caráter cada vez mais público dos resultados do PISA é, por si só, um fator de geração de apoio a essa agenda, pois os resultados até o momento foram interpretados para mostrar que as nações líderes estão buscando o tipo de estratégia de profissionalização do professor que defendo aqui.

Em um sistema grande e descentralizado como o nosso, não é realista esperar uma transformação da noite para o dia; no entanto, é possível que um conjunto de esforços combinados puxando na mesma direção possa gradualmente produzir um tipo de setor bastante diferente. Dois exemplos finais ilustram as possibilidades. Os cuidados de saúde nos EUA foram o caso paradigmático para a teoria da dependência de trajetória - o fato de que os Estados Unidos inicialmente desenvolveram sua prestação de cuidados de saúde por meio de um mercado privado em vez de um bem público, argumentaram os teóricos, tornou muito mais difícil para a reforma subsequente avançar em direção ao atendimento universal porque os interesses organizados tinham o poder de evitar tais mudanças. Essa lógica parecia inabalável - até mudar, quando a Lei de Cuidados Acessíveis de 2010 foi aprovada. A maneira que passou não estava na forma que muitos defensores do sistema de saúde universal esperavam - sistema de saúde de pagador único administrado pelo governo, que, argumentaram, as evidências comparativas sugeriam que seriam menos caros e mais eficazes. Em vez disso, o programa aprovado era um compromisso públicoprivado que lida com seguradoras existentes e, essencialmente, criando uma forma híbrida a partir da realidade presente, em vez do que um projetista de sistema poderia ter criado a partir do zero. Da mesma forma, mudar a educação em uma direção mais profissional exigirá construção a partir de nossas instituições existentes, em vez de criar um novo sistema fora de todo o plano.

Um exemplo de Ontário, Canadá, mostra o que pode ser possível. De 1997 a 2003, uma relação amarga entre a liderança provincial e os professores e seus sindicatos foi generalizada. 0 governo veiculou anúncios na televisão demonizando os professores, reduziu o tempo de desenvolvimento profissional pela metade e cortou o financiamento; os sindicatos responderam com inúmeras e prolongadas greves. Em 2003, com a eleição de um novo premier, Dalton McGuinty, uma nova equipe formada que estava determinada a fazer as pazes com os sindicatos e trabalhar juntos em direção ao objetivo de longo prazo 
de melhorar o desempenho dos alunos. A liderança, sindicatos e outros grupos começaram a se reunir trimestralmente para discutir questões-chave; eles firmaram uma paz trabalhista de longo prazo em 2005. A liderança provincial procurou ativamente por pontos win-win com os sindicatos, como mais tempo de planejamento comum e financiamento de um cargo extra para um coordenador de prevenção do abandono escolar. Essas condições estáveis pavimentaram o caminho para uma estratégia de capacitação de longo prazo em relação à alfabetização e a aritmética, bem como para um impulso para aumentar as taxas de conclusão do ensino médio. Em 2010, a taxa de graduação aumentou de 68\% para 79\%, e a porcentagem de alunos do ensino fundamental aprovados em exames de matemática, alfabetização e ciências aumentou de 55\% para 70\% (MEHTA \& SCHWARTZ, 2010). O clima dentro do sistema também melhorou muito, com pesquisas de professores revelando que eles estavam tão felizes em estar trabalhando no sistema da mesma forma que em qualquer momento de sua gestão. Embora a escala do desafio seja grande, esses exemplos sugerem que, mesmo dentro de um período de tempo relativamente curto, mudanças significativas nos resultados e no espírito de um sistema são possíveis.

\section{Referências}

AMERICAN FEDERATION OF TEACHERS (AFT). Raising the bar: Aligning and elevating teacher preparation and the teaching profession. Washington, DC: Author, 2012

AU, W. Teaching under the new Taylorism: High-stakes testing and the standardization of the 21st century curriculum. Journal of Curriculum Studies, 43(1), 25-45, 2011

AUSTIN, J., SCHWARTZ, R., \& SUESSE, J. Long Beach Unified School District (A): Change that leads to improvement (1992-2002). Cambridge, MA: Public Education Leadership Project, 2004

BARBER, M., \& MOURSHED, M.. How the world's best-performing school systems come out on top. London: McKinsey, 2007.

CALLAHAN, R. Education and the cult of efficiency. Chicago: University of Chicago Press, 1962.

CHARLOT, J., TRAN, D., \& STEMM-CALDERON, Z.. Theories of learning and a body of knowledge. Unpublished working paper, Harvard Graduate School of Education, 2013.

CHI, M., GLASER, R., \& FARR, M. J. (Eds). The nature of expertise. Hillsdale, NJ: Lawrence Erlbaum, 1988. 
CHILDRESS, S. ET AL. . Leading for equity: The pursuit of excellence in the Montgomery County schools. Cambridge, MA: Harvard Education Press, 2009.

CIMINO, J. . Development of expertise in medical practice. In: R. STERNBERG \& J. HORVATH (Eds.). Tacit knowledge in professional practice (pp.101-119). Mahwah, NJ: Lawrence Erlbaum, 1999.

CLIFFORD, G. J., \& GUTHRIE, J. W. Ed school: A brief for professional education. Chicago: University of Chicago Press, 1988.

COHEN, D.. Teaching practice: Plus ça change. In: JACKSON, P. W. (Ed.), Contributing to educational change: Perspectives on research and practice (pp. 27-84). Berkeley, CA: McCutchan, 1988

COHEN, D. Teaching and its predicaments. Cambridge, MA: Harvard University Press, 2011.

COHEN, D. K., \& MOFFITT, S. L. The ordeal of equality: Did federal regulation fix the schools? Cambridge, MA: Harvard University Press, 2009.

COUNCIL OF CHIEF STATE SCHOOL OFFICERS.. Our responsibility, our promise: Transforming educator preparation and entry into the profession. Washington, DC: Author, 2012.

CUBAN, L.. How teachers taught: Constancy and change in American classrooms. New York: Teachers College Press, 1984.

CUBBERLEY, E. P. Public school administration. Boston: Houghton Mifflin, 1916.

DARLING-HAMMOND, L. The flat world and education. New York: Teachers College Press, 2010.

DEWEY, J. The University School. University Record (University of Chicago), 1, 417- 419, 1896.

ELMORE, R. Getting to scale with good educational practice. Harvard Educational Review, 66(1), 1-26, 1996.

FORZANI, F. M. The work of reform in teacher education. (Order No. 3492731, University of Michigan). ProQuest Dissertations and Theses, 357, 2011.

FULLAN, M., GALLUZZO, G., MORRIS, P., \& WATSON, N. The rise and stall of teacher education reform. Washington, DC: American Association of Colleges for Teacher Education, 1998.

GATTO, J. Weapons of mass instruction: A schoolteacher's journey through the dark world of compulsory schooling. Gabriola Island, British Columbia: New Society, 2009.

GOODLAD, J. A place called school: Promise for the future. New York: McGraw Hill, 1984. GOODMAN, J. (2013). Charter management organizations and the regulated environment: Is it worth the price? Educational Researcher, 42(2), 89-96, 2013. 
GROSSMAN, P., \& MCDONALD, M. Back to the future: Directions for research in teaching and teacher education. American Educational Research Journal, 45(1), 184-205, 2008.

HACKER, J. The historical logic of national health insurance: Structure and sequence in the development of British, Canadian and U.S. medical policy. Studies in American Political Development, 12, 57-130, 1998.

HESS, F. Spinning wheels: The politics of urban school reform. Washington, DC: Brookings Institution, 1998.

HIEBERT, J., GALLIMORE, R., \& STIGLER, J. A knowledge base for the teaching profession: What would it look like and how can we get one? Educational Researcher, 31(5),3-15, 2002.

HILL, H. Learning in the teacher workforce. Future of Children, 17(1), 111-127, 2007.

JACKSON, P. Life in classrooms. New York: Holt, Rinehart, \& Winston, 1968.

JENCKS, C., \& RIESMAN, D. The academic revolution. Garden City, NY: Doubleday, 1968.

KAHLENBERG, R. Tough liberal: Albert Shanker and the battles over schools, race and democracy. New York: Columbia University Press, 2007.

KERCHNER, C., KOPPICH, J., \& WEERES, J. United mind workers: Unions and teaching in the knowledge society. San Francisco: Jossey-Bass, 1997.

LAGEMANN, E. An elusive science. Chicago: University of Chicago Press, 2000.

LANIER, J., \& LITTLE, J. W. Research on teacher education. In M. Wittrock (Ed.), Handbook of research on teaching (3rd ed., pp. 527-559). New York: Macmillan, 1986.

LEVIN, B. How to change 5000 schools: A practical and positive approach for leading change at every level. Cambridge, MA: Harvard Education Press, 2008.

LEVINE, A. Educating school teachers. Washington, DC: Education Schools Project, 2006.

LIVINGSTON, C., \& BORKO, H.. Expert-novice differences in teaching: A cognitive analysis and implications for teacher education. Journal of Teacher Education, 40(4), 36-42, 1989.

LORTIE, D. C. Schoolteacher: A sociological study. Chicago: University of Chicago Press, 1975.

MEASURES OF EFFECTIVE TEACHING PROJECT. Gathering feedback for teaching. Seattle: Gates Foundation, 2012.

MEHTA, J. The allure of order: High hopes, dashed expectations and the troubled quest to remake American schooling. New York: Oxford University Press, 2013

MEHTA, J., \& DOCTOR, J. A board exam for teaching. Phi Delta Kappan, 94(7), 8-13, 2013.

MEHTA, J., GOMEZ, L., \& BRYK, A. S. Building on practical knowledge: The key to a stronger profession is learning from the field. In J. Mehta, R. B. Schwartz, \& F. M, 2012. 
HESS (Eds.). The futures of school reform. Cambridge, MA: Harvard Education Press.

MEHTA, J., \& SCHWARTZ, R. Ontario, Canada: Reform to support high achievement in a diverse context. In: SCLEICHER, A. \& HOPPER, R. (Eds.), Strong performers and successful reformers in education: Lessons from PISA. Paris: OECD, 2010.

MEHTA, J., \& TELES, S. Jurisdictional politics: A new federal role in education. In: HESS, F. \& KELLY, A. (Eds.), Carrots, sticks, and the bully pulpit: Lessons from a half-century of federal efforts to improve America's schools. Cambridge, MA: Harvard Education Press, 2011.

MEHTA, J., \& WINSHIP, C.. "Moral power.” In: HITLIN, S. and VAISEY, S. (Eds.), Handbook of the sociology of morality (pp. 425-438). New York: Springer, 2010.

MEYER, J. W., \& ROWAN, B.. Institutionalized organizations: Formal structure as myth and ceremony. American Journal of Sociology, 83(2), 340-363, 1977.

MINTZBERG, H. (1993). Structure in fives: Designing effective organizations. Englewood Cliffs, NJ: Prentice Hall, 1993.

MOE, T. Special interest: Teachers unions and America's public schools. Washington, DC: Brookings Institution, 2011.

NATIONAL EDUCATION ASSOCIATION (NEA). Transforming teaching: Connecting professional responsibility with student learning. Washington, DC: Author, 2012

NATIONAL GOVERNORS' ASSOCIATION. Center for Policy Research, Thomas H. Kean, Lamar Alexander, and Bill Clinton. Time for results: The governors' 1991 report on education. Washington, DC: Author, 1986.

OSBORNE, D., \& GAEBLER, T. Reinventing government: How the entrepreneurial spirit is transforming the public sector. Reading, MA: Addison-Wesley, 1992.

Organisation of Economic Co-operation and Development [OECD]. Strong performer and successful reformers in education: Lessons from PISA for the United States. Paris: OECD, 2010

PAYNE, C. So much reform, so little change: The persistence of failure in American public schools. Cambridge, MA: Harvard Education Press, 2008.

PERROW, C. A framework for the comparative analysis of organizations. American Sociological Review, 32(2), 194-208, 1967.

PEURACH, D. Seeing complexity in public education: Problems, possibilities and success for all. New York: Oxford University Press, 2011.

PIERSON, P. Increasing returns, path dependence, and the study of politics. American Political Science Review, 94(2), 251-267, 2000.

ROSSI, P. The iron law of evaluation and other metallic rules. Research in Social Problems and Public Policy, 4, 3-20, 1987.

ROWAN, B. Commitment and control: Alternative strategies for the organizational design of schools. Review of Research in Education, 16(1), 353-389, 1990. 
SAPHIER, J., HALEY-SPECA, M., \& GOWER, R. (2008). The skillful teacher: Building your teaching skills. Acton, MA: Research for Better Teaching, Inc.

SCHNEIDER, B., \& MCDONALD, S. (Eds). (2007). Scale-up in education: Issues in practice. Lanham, MD: Rowan \& Littlefield.

SHULMAN, L. (1987). Knowledge and teaching: Foundations of the new reform. Harvard Educational Review, 57(1), 1-21.

STARR, P. (1982). The social transformation of American medicine. New York: Basic Books.

STINCHCOMBE, A. L. (1965). Social structure and organizations. In J. G. March (Ed.), Handbook of organizations (pp. 142-193). New York: Rand McNally.

TOCH, T. (1991). In the name of excellence: The struggle to reform the nation's schools, why it's failing, and what should be done. New York: Oxford University Press.

TOCH, T. Sweating the big stuff: A progress report on efforts to scale up the nation's best charter schools. Unpublished manuscript, 2009

TYACK, D. The one best system. Cambridge, MA: Harvard University Press, 1974.

TYACK, D., \& CUBAN, L. Tinkering toward utopia: A century of public school reform. Cambridge, MA: Harvard University Press, 1995.

WEICK, K. Educational organizations as loosely coupled systems. Administrative Science Quarterly, 21(1), 1-19, 1976.

WISE, A. Legislated learning: The bureaucratization of the American classroom. Berkeley: University of California Press, 1979. 

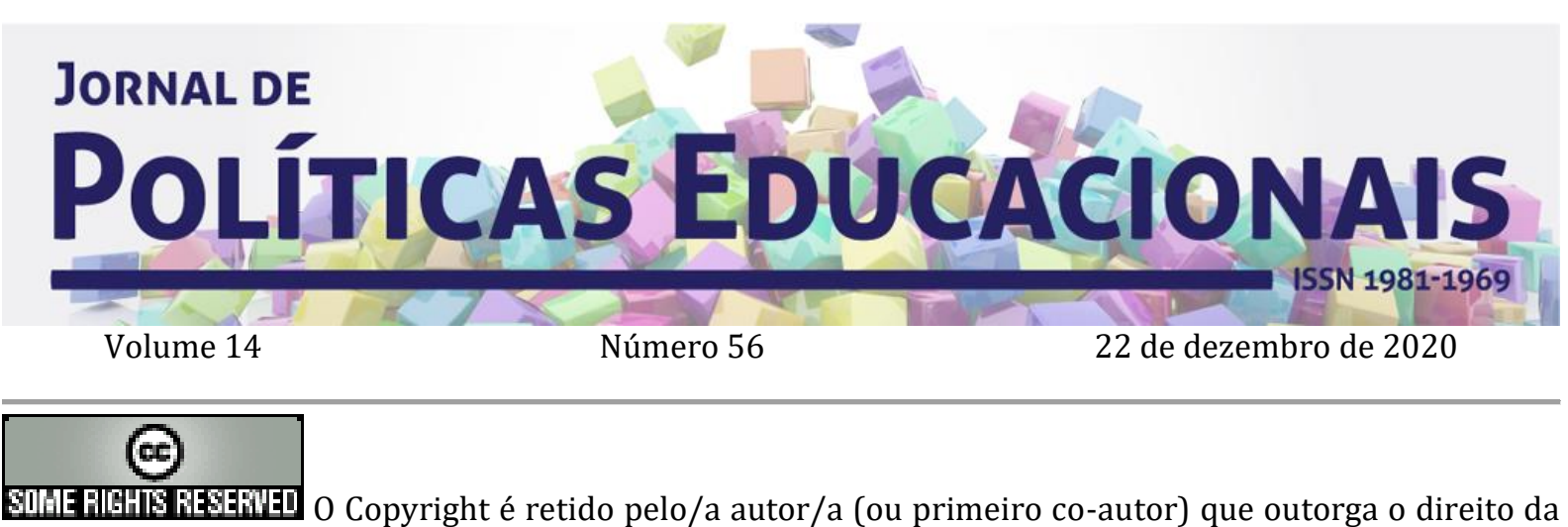

O Copyright é retido pelo/a autor/a (ou primeiro co-autor) que outorga o direito da primeira publicação ao Jornal de Políticas Educacionais. Mais informação da licença de Creative Commons encontram-se em http://creativecommons.org/licenses/by-nc-nd/2.5. Qualquer outro uso deve ser aprovado em conjunto pelo/s autor/es e pelo periódico.

JoRNAL DE POLÍTICAS EDUCACIONAIS é uma publicação do Núcleo de Políticas Educacionais do Setor de Educação da Universidade Federal do Paraná - NuPE/UFPR, em consórcio com a Linha de Pesquisa em Políticas Educacionais do Programa de Pós-Graduação em Educação - PPGE/UFPR, que aceita colaboração, reservando-se o direito de publicar ou não o material espontaneamente enviado à redação. As colaborações devem ser enviadas ao NuPE/UFPR, conforme orientações contidas nas páginas do periódico na internet: http://revistas.ufpr.br/jpe.

\author{
Indexação: \\ BBE - Biblioteca Brasileira de Educação (MEC/INEP) \\ Clase (Base de Datos Bibliográfica de Revistas de Ciencias Sociales y Humanidades) \\ Diadorim - Diretório de Política de Acesso Aberto das Revistas Científicas Brasileiras (IBICT) \\ Google Scholar \\ Index Copernicus \\ Portal de Periódicos (CAPES) \\ SER - Sistema Eletrônico de Revistas da Universidade Federal do Paraná (SER/UFPR) \\ Sumários de Revistas Brasileiras (FUNPEC-RP) \\ DRII - Directory of Research Journals Indexing
}

(Periódico integralmente disponível apenas em via eletrônica)

Jornal de Políticas Educacionais / Núcleo de Políticas Educacionais da Universidade Federal do Paraná -

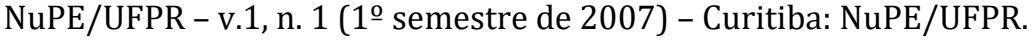

Volume 14, número 56 - Dezembro de 2020

ISSN 1981-1969

1. Educação - Periódicos. 2. Política Educacional - Periódicos. I. NuPE/UFPR

Comitê Editorial:

Elisângela Scaff (UFPR)

Daniela de Oliveira Pires (UFPR)

Conselho Editorial:

Andréa Barbosa Gouveia (UFPR - Brasil), Cesar Tello (Universidad Nacional Tres Febrero, Argentina), Fernanda Saforcada (Universidad de Buenos Aires - UBA - Argentina), Gladys Beatriz Barreyro (USP Brasil), Gustavo Enrique Fischman, (Arizona State University - USA), Jefferson Mainardes (UEPG - Brasil), 
João Ferreira de Oliveira (UFG - Brasil), Juca Gil (UFRGS - Brasil), Luiz Souza Júnior (UFPB - Brasil), Ney Cristina Monteiro de Oliveira (UFPA - Brasil), Nicolás Bentancur, (Universidad de la República de Uruguay), Robert Verhine (UFBA - Brasil), Rosana Cruz (UFPI - Brasil), Rubens Barbosa Camargo (USP - Brasil), Sebastián Donoso Díaz (Universidad de Talca - Chile), TheresaAdrião (UNICAMP - Brasil), Vera Peroni (UFRGS - Brasil).

Créditos e Agradecimentos:

Revisão de Língua Portuguesa, Abstract e Resumen: PROGRAMA DE APOIO ÀS PUBLICAÇõES CIENTÍFICAS PERIÓDICAS DA UFPR

Arte e diagramação: TIAGO TAVARES (tiagotav@gmail.com)

Jornal de Políticas Educacionais

Universidade Federal do Paraná

Setor de Educação

Núcleo de Políticas Educacionais - NuPE/UFPR

Avenida Sete de Setembro, 2645

2 o andar, Sala 213

80.230-010 - Curitiba - PR - Brasil

Tel.: 41-3535-6264

jpe@ufpr.br

http://revistas.ufpr.br/jpe 